\title{
Flood Mapping in the Coastal Region of Bangladesh Using Sentinel-1 SAR Images: A Case Study of Super Cyclone Amphan
}

\author{
Pollen Chakma ${ }^{1}$, Aysha Akter ${ }^{2^{*}}$ \\ ${ }^{1}$ Department of Water Resources Engineering, Chittagong University of Engineering and Technology, Chittagong, BANGLADESH \\ Pahartoli, Raozan, Chittagong - 4349, Bangladesh \\ 2Department of Civil Engineering, Chittagong University of Engineering and Technology, Chittagong, BANGLADESH \\ Pahartoli, Raozan, Chittagong - 4349, Bangladesh \\ Corresponding authors: aysha_akter@cuet.ac.bd
}

SUBMITTED 03 March 2021 REVISED 15 April 2021 ACCEPTED 28 April 2021

\begin{abstract}
Floods are triggered by water overflow into drylands from several sources, including rivers, lakes, oceans, or heavy rainfall. Near realtime (NRT) flood mapping plays an important role in taking strategic measures to reduce flood damage after a flood event. There are many satellite imagery based remote sensing techniques that are widely used to generate flood maps. Synthetic aperture radar (SAR) images have proven to be more effective in flood mapping due to its high spatial resolution and cloud penetration capacity. This case study is focused on the super cyclone, commonly known as Amphan, stemming from the west Bengal-Bangladesh coast across the Sundarbans on 20 May 2020 , with a wind speed between $155 \mathrm{kmph}-165 \mathrm{kmph}$ gusting up to $185 \mathrm{kmph}$. The flooding extent is determined by analyzing the pre and post-event synthetic aperture radar images, using the change detection and thresholding (CDAT) method. The $\mathrm{km}^{2}$ results showed an inundated landmass of $2146 \mathrm{~km}^{2}$ on 22 May 2020, excluding Sundarban. However, the area became $1425 \mathrm{~km}^{2}$ about a week after the event, precisely on $28 \mathrm{May} 2020 \mathrm{~km}^{2}$. This persistency generated a more severe and intense flood, due to the broken embankments. Furthermore, 13 out of 19 coastal districts were affected by the flooding, while 8 were highly inundated, including Bagerhat, Pirojpur, Satkhira, Khulna, Barisal, Jhalokati, Patuakhali and Barguna. These findings were subsequently compared with an inundation map created with a validation survey immediately after the event and also with the disposed location using a machine learning-based image classification technique. Consequently, the comparison showed a close similarity between the inundation scenario and the flood reports from the secondary sources. This circumstance envisages the significant role of CDAT application in providing relevant information for an effective decision support system.
\end{abstract}

KEYWORDS Super Cyclone Amphan; Storm Surge; Flood Mapping; SAR; Sentinel-1; Google Earth Engine.

(c) The Author(s) 2021. This article is distributed under a Creative Commons Attribution-ShareAlike 4.0 International license.

\section{INTRODUCTION}

Cyclonic storm surge-related inundation appears common in Bangladesh's coastal regions, due to the location within the world's largest tidedominated delta, termed Ganges-BrahmaputraMeghna (GBM). However, there is a general occurrence mainly during early summer (AprilMay) and late rainy season (October-November) (Debsarma, 2009, Dasgupta et al., 2010). Bengal bay plays a very significant role in developing these cyclones, with approximately $7 \%$ targeting the coast (Ali, 1999). This condition generated a more severe effect, as $53 \%$ of the global cyclonerelated deaths reportedly occurred in Bangladesh (Debsarma, 2009). Also, cyclonic storm surge causes disastrous floods due to a shallow continental shelf (Murty, Flather \& Henry, 1986), coastal funneling shape (Das,1972) and triangular structure in the northeast corner of the Meghna Estuary (Flierl \& Robinson, 1972,
Haider et al., 1991). Therefore, the resulting flood intensity greatly expanded during high currents from the tide-surge interactions (Debsarma, 2009).

The super cyclone triggered a landfall over the West Bengal-Bangladesh coast on 20 May 2020, between 10:00-12:00, UTC. This is the first Amphan recorded after the Odisha occurrence in 1999 (RSMC-Tropical Cyclones, 2021). A postevent survey conducted by Area Cyclone Warning Centre (ACWC), Kolkata, reported lowlying areas in the south and north Pargana and the adjoining regions of east Medinipur in west Bengal received $4.6 \mathrm{~m}$ high storm surge during the flood (RSMC-Tropical Cyclones, 2021). As a consequence, 2.6 million persons in 19 districts (second administrative boundary) were affected, alongside a total of 76 Upazilas (third 
administrative boundary) with 34 inundated regions. Under these circumstances, $550 \mathrm{~km}$ of roads and embankments have been damaged (Needs Assessment Working Group, 2020).

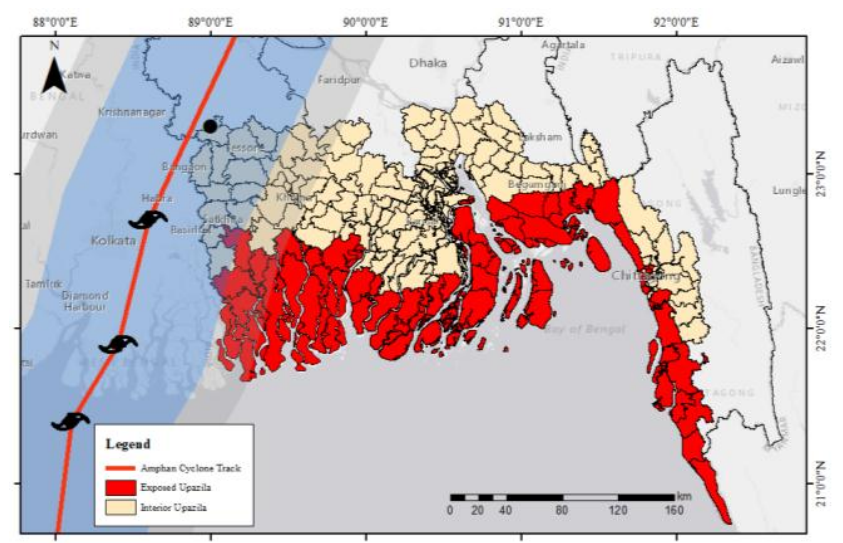

Figure 1. The Amphan cyclone tracks over the study area.

Flooding is a widespread phenomenon in lowland countries, including Bangladesh. Therefore, an immediate supply of disaster relief to the affected areas becomes very necessary, including proximate real-time flood maps. These charts are also necessary for the planning and policymaking stages. However, the water levelbased illustrations are unable to provide an accurate spatial extent of the overflow (Huang, Chen \& Wu, 2014). Also, constructing a flood map using field survey data immediately after a severe flood event appears challenging and unsuitable for massive landmass.

Conversely, satellite-based flood maps tend to provide adjacent real-time representations with various spatial resolutions over time and higher accuracy (Singha et al., 2020). These techniques are divided into two categories. The first refers to flood mapping using a passive optical sensor, while the second employs the active option. Passive optical sensors use solar reflectance and are unable to capture images under cloud cover, but the active devices rely on signals capable of penetrating the barrier. This competence offers the material suitability for flood mapping (Long, Fatoyinbo \& Policelli, 2014, Clement, Kilsby \& Moore, 2018), e. $g$ the synthetic aperture radar (SAR). Furthermore, the water surfaces and flooded areas appears relatively dark due to low backscattering signals in the SAR images. This condition forms a separate behavior in the water surfaces compared to other landforms. However, flood detection using SAR imagery is accompanied with certain limitations. For instance, during a flood event, windy conditions potentially develop particular water surface roughness. This circumstance creates various challenges in classifying the areas (Brisco et al., 2009), where radar shadows in SAR images are mistakenly categorized as flooded regions (Mason et al., 2010).

Several SAR-based flood mapping methods are applied across the world, including interferometric coherence change detection (Nico et al., 2000), active contour model (Horritt, 1999) and thresholding (Henry et al., 2006). Occasionally, the processes are improved by combining with other techniques. For instance, an active contour is merged with the digital terrain model (Mason et al., 2007) and thresholding. Furthermore, the thresholding method is joined with segmentation (Mason et al., 2012), digital elevation model (DEM), filling (Brivio et al., 2002), hydrologic modeling (Schumann et al., 2010), change detection (Long, Fatoyinbo \& Policelli, 2014, Clement, Kilsby \& Moore, 2018, Singha et al., 2020), region growing and change detection (Matgen et al., 2011), fuzzy logic and region growing (Martinis, Kersten \& Twele, 2015), multi-temporal statistics (Cian, Marconcini \& Ceccato, 2018), and probabilistic change detection (Schlaffer et al., 2017). Several researches also adopt machine learning-based techniques for detecting flood water using SAR imagery. Examples include artificial neural network (ANN) (Sarker et al., 2019, Tien, Bui et al., 2020), k-nearest neighbors (KNN) (Aristizabal, Judge, \& Monsivais-Huertero, 2020), random forest (RF) (Chaabani et al., 2018, Woznicki et al., 2019) and support vector machines (SVM) (Tehrany et al., 2015, Insom et al., 2015).

Numerous studies have also employed SAR images to map and monitor various flood events in Bangladesh. In addition, RADARSAT snapshots were used to explore the flooded areas for varying occurrences in other regions. 
Inundations between 2004-2007 have been analyzed using MODIS and RADARSAT images (Islam, Bala, \&Haque, 2010), while LANDSAT-7 data were utilized alongside RADARSAT for mapping floods from 2000-2004 in the northeastern zone (Hoque et al., 2011) (Chowdhury \& Hassan, 2017). Similarly, Sentinel-1 SAR photos were adopted in 2017 (Uddin, Matin \&Meyer, 2019) to analyze the spatial flood dynamics (Hassan et al., 2020). These images also aided the detection of spatiotemporal patterns of the flood events between 2014-2018, with a focus on paddy rice fields (Singha et al., 2020).

This study also adopted the Sentinel-1 SAR images, with high spatial resolution ranging from $5 \times 5 \mathrm{~m}$ to $20 \times 40 \mathrm{~m}$ based on the acquisition mode and processing level, although the temporal resolution was 6 days (ESA, 2012). The CDAT method, described as fast and straightforward, was used to detect the flooded segments (Cian, Marconcini \& Ceccato, 2018). Subsequently, the image processing and SAR analysis were achieved using Google Earth Engine (GEE). The advantage of this cloud computing platform is that the applied Sentinel1 dataset and other satellite resources are also stored. These diagrams are radiometrically calibrated and terrain corrected (Clement, Kilsby \& Moore, 2018) to ensure cost-effectiveness, in terms of data storage and computation time. Therefore, the purpose of this study is to determine the spatial extent of inundation caused by the super cyclone, Amphan, in Bangladesh's coastal regions. Figure 1 represents the research location, including the original flood track. Under this analysis, single pre-event and double post-event SAR images were evaluated.

\section{METHODOLOGY}

This study encompasses flooded area detection using satellite images, followed by verification and validation with secondary data. Also, highresolution C-band SAR diagrams from the Sentinel-1 SAR GRD dataset were acquired for pre and post-Amphan cyclone events. These illustrations were obtained on 16 May 2020 for pre-cyclone, while 22and 28th featured the postcyclone effect. Image processing for detecting flooded areas was conducted using the GEE platform. The Sentinel-1 satellite employed 4 acquisition modes, termed strip map (SM), interferometric wide swath (IW), extra-wide swath (EW) and wave (WV). However, only the IW was used for land surface capture (Torres et al., 2012), although Sentinel-1obtains images in $\mathrm{VH}$ (vertical transmit and horizontal receive) and VV (vertical transmit and vertical receive) polarization in IW acquisition mode. Several researches showed that co-polarized (VV and $\mathrm{HH})$ pictures have advantages over crosspolarized ( $\mathrm{VH}$ and $\mathrm{HV}$ ), in terms of flooded area identification (Twele et al., 2016). Previous studies suggested that VV samples are less prone to wrong classification (Clement, Kilsby \& Moore, 2018), but this study solely adopted the VV option. Meanwhile, the CDAT methods were used to detect flooded areas, as proposed by Long et al. (Long, Fatoyinbo \& Policelli, 2014), due to its proven reliability in earlier related studies (Long, Fatoyinbo \& Policelli, 2014, Clement, Kilsby \&Moore, 2018), including an analysis in Bangladesh between 2014-2018 (Singha et al., 2020). As a consequence, more accurate and superior flood maps are obtained (Matgen et al., 2011). Furthermore, pre and post-cyclone images were extracted from the Sentinel-1 GRD dataset by filtering based on date, acquisition mode and GEE polarization. The reference sample (R) is the non-flooded image acquired before the cyclone (16 May 2020). Proper selection of reference representations plays a significant role in detecting the flooded areas using SAR data (Hostache, Matgen \&Wagner, 2012). Generally, the driest period is preferred for the reference image collection (Clement, Kilsby \& Moore, 2018, Singha et al., 2020). Average rainfall of $200 \mathrm{~mm}$ is observed depending on the CHIRPS data (Hassan et al., 2020). In this reported study, the period was selected before the Amphan event to avoid heavy rainfall in the research location. Therefore, the reference images indicate realistic wetlands, while presenting the flooded areas. Also, the post-cyclone effects were specified after the landfall for days 1 and 7 . 
Subsequently, a filter was applied to the reference and flood images to eliminate noise. The famous Lee filter was employed with a window size of $7 \times 7$ and a separate image was generated, using the variations in the backscattering differences between the pre-and post-cyclone captures. In the various illustrations, the flooded areas appeared dark while non-flooded, or regions with no changes were grey.

A threshold value was applied to the difference image to extract only the areas with additional inundation probability. The flooded pixels (PF) was identified using equation (1), as formulated by Long et al. (Long, Fatoyinbo \& Policelli, 2014):

$\mathrm{PF}<(\{\mu[\mathrm{D}]\}-\mathrm{fc} \times\{\sigma[\mathrm{D}]\})$

Where, $\mu[D]$ and $\sigma[D]$ is the mean and standard deviation of the difference image(D), and $\mathrm{fc}$ is a coefficient with an assumed optimal value of 1.5.

Under this threshold criterion, the pixels are considered flooded with value less than the mean pixel minus 1.5 times the image standard. Therefore, flooded pixels were detected for both post-flood images on 22 and 28 May, with subsequent map generation. These plots were manually analyzed using GIS tools to obtain the flooding scenario at the district and Upazila levels.

The collection of ground observation data in the affected areas was deferred due to the COVID-19 lockdown. However, the result accuracy was validated using two separate secondary data sources because of the reliability, either as actual field data or validated sources from previous related studies. In the first step, the validation is achieved by comparing the total inundated areas based on a machine learning classification technique, termed support vector machines (SVM), in addition to using SAR imagery (Hassan et al., 2020). This is followed by the use of an inundation map for the post-Amphan event, based on primary field data from the Needs Assessment Working Group (NAWG) survey, Bangladesh. The methodology used in this study is illustrated using a workflow diagram in Figure 2.

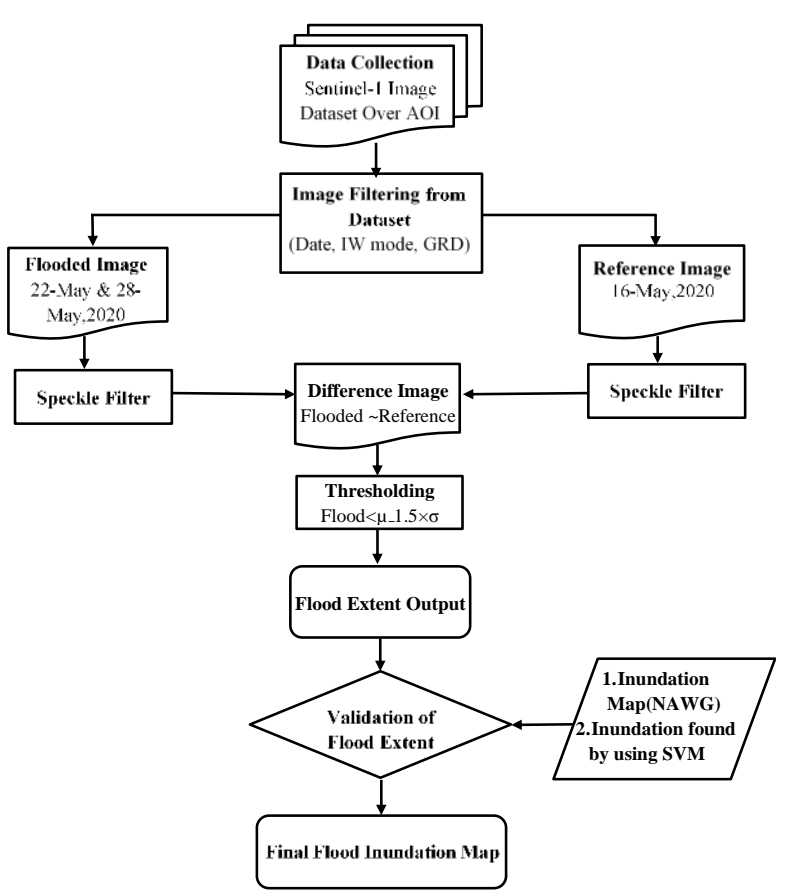

Figure 2. Workflow diagram of the methodology used in this study.

\section{RESULTS AND DISCUSSION}

\subsection{The flooded area by CDAT method}

Amphan storm surge, alongside heavy rainfall, instigated the flooding. The affected regions were detected using the CDAT method and were further analyzed with a GIS tool to identify the sites, after preparing the flood extent map with the SAR data. This analysis showed $\mathrm{km}^{2}$ an inundated landmass of $2146 \mathrm{~km}^{2}$ on 22 May 2020, a day after the event, excluding the Sundarban. Among the 19 coastal districts, 13 were affected due to the flood. Table 1 shows that 8 locations, including Bagerhat, Pirojpur, Satkhira, Khulna, Barisal, Jhalokati, Patuakhali, and Barguna, obtained the highest inundation area of $376 \mathrm{~km}^{2}$, $300 \mathrm{~km}^{2}, 239 \mathrm{~km}^{2}, 238 \mathrm{~km}^{2}, 238 \mathrm{~km}^{2}, 220 \mathrm{~km}^{2}$, $204 \mathrm{~km}^{2}$ and $117 \mathrm{~km}^{2}$,respectively. However, $26.35 \%$ of the total dimension occurred in Jhalokati, while Pirojpur and Bagerhat covered more than 15\%. Furthermore, Khulna, Satkhira, and Barisal reported an inundation area of approximately $10 \%$.

In Bagherhat district, Mongla, Morrelganj, Rampal, Sarankhola were the Upazilas with the 
maximum percentages, estimated at $30 \%$ of the total area. Figure 4 shows Betagi, Bakerganj, Tungipara, Kanthalia, Nalchity, Rajapur, Paikgacha, Mirzaganj, Bhandaria, Kawkhali, Mathabaria, Zianagar as the most affected Upazilas with over $25 \%$ inundation.

Precisely on 28 May, virtually a week after the Amphan event, the total inundation area reduced to $1429 \mathrm{~km}^{2} \mathrm{~km}^{2}$, with no significant change in most districts. Meanwhile, the percentages of inundation areas remain unaltered in Bagerhat, Satkhira, Khulna, Patuakhali, Jessore and Lakshmipur, due to the broken embankments. Generally, $76 \mathrm{~km}$ embankments have been reportedly damaged by the cyclone Amphan (Needs Assessment Working Group, 2020). These structures were supposed to prevent water influx into the inland during high tides. Table 1 and Figure 3 show the changes in the inundation area on 22 and 28 May, respectively, indicating the flood severity. Conversely, flood water abated significantly in Pirojpur, Barisal, and Jhalokati, but demonstrated an increase in the inundation area for Barguna, Gopalganj, and Narail, due to a higher river discharge. As earlier mentioned, the extreme precipitation instigated the excessive river overflow, resulting in a more severe postAmphan situation in certain regions.

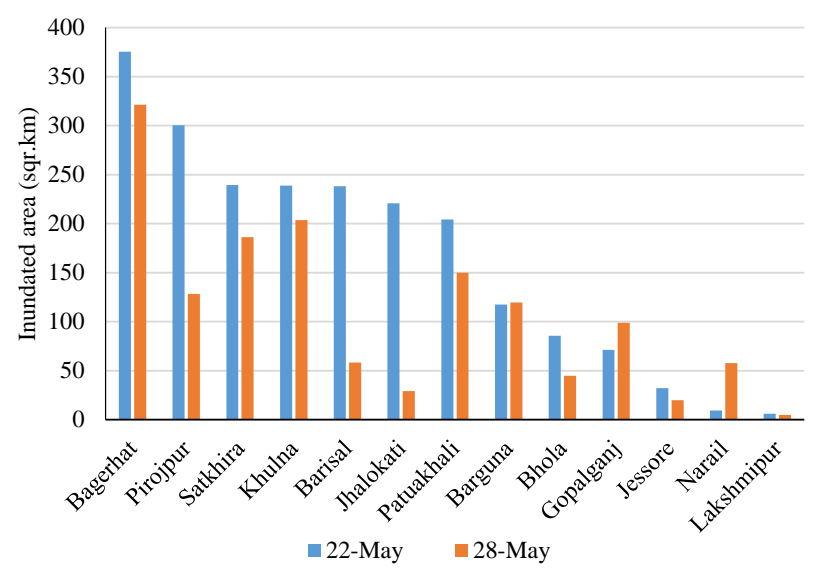

Figure 3. Total inundation area in affected districts on 22 May and 28 May.

Figure 4 represents the inundation area percentages on 22 and 28 May for separate Upazilas in the affected districts. Based on Figure 5 , most of the areas were known to retain the flood a week after the occurrence, similar to a scenario in Figure 6. Furthermore, the majority of the Upazilas demonstrated minimal reductions in inundation areas or no recorded relevant changes. Virtually, the entire Upazilas in Jhalokati and Pirojpur showed a significant decline in inundation area percentage. Figures 5(g) and 5(l) reflect a rapid floodwater withdrawal in these regions, compared to the remaining affected Upazilas.

Table 1. List of the flooded districts.

\begin{tabular}{llcccc} 
& & \multicolumn{2}{c}{22 May 2020 } & \multicolumn{2}{c}{28 May 2020 } \\
\cline { 3 - 6 } District & Division & $\begin{array}{c}\text { Inundation } \\
\text { Area }\left(\mathrm{km}^{2}\right)\end{array}$ & $\begin{array}{c}\text { Inundation Area } \\
\text { (in \% of total area) }\end{array}$ & $\begin{array}{c}\text { Inundation } \\
\text { Area }\left(\mathrm{km}^{2}\right)\end{array}$ & $\begin{array}{c}\text { Inundation Area(in } \\
\% \text { of total area) }\end{array}$ \\
\hline Bagerhat & Khulna & 375 & 15.99 & 321 & 13.68 \\
Pirojpur & Barisal & 300 & 21.93 & 128 & 9.38 \\
Satkhira & Khulna & 239 & 8.87 & 203 & 6.89 \\
Khulna & Khulna & 238 & 9.66 & 58 & 8.25 \\
Barisal & Barisal & 238 & 9.32 & 29 & 2.29 \\
Jhalokati & Barisal & 220 & 26.35 & 149 & 3.49 \\
Patuakhali & Barisal & 204 & 7.32 & 44 & 5.38 \\
Barguna & Barisal & 117 & 7.75 & 99 & 7.89 \\
Bhola & Barisal & 85 & 3.96 & 19 & 2.08 \\
Gopalganj & Dhaka & 71 & 4.06 & 57 & 5.64 \\
Jessore & Khulna & 32 & 1.05 & 5 & 0.65 \\
Narail & Khulna & 9 & 0.79 & 0.41 & 4.85 \\
Lakshmipur & Chittagong & 6 & & 5.34 \\
\hline
\end{tabular}




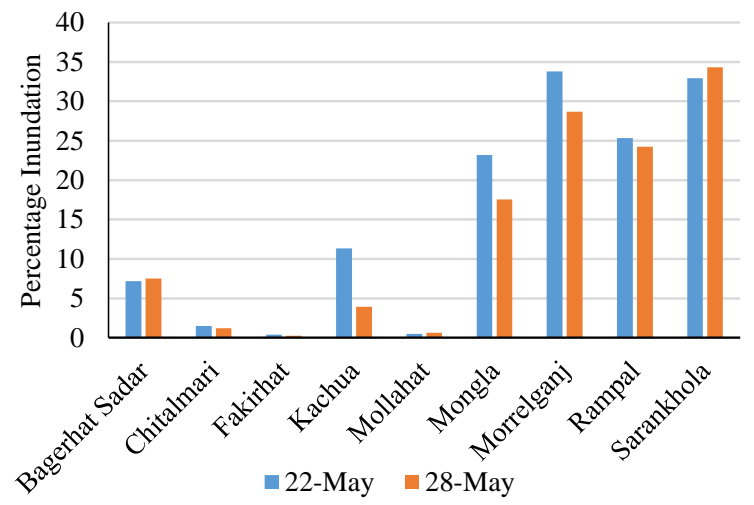

(a) Bagerhat District

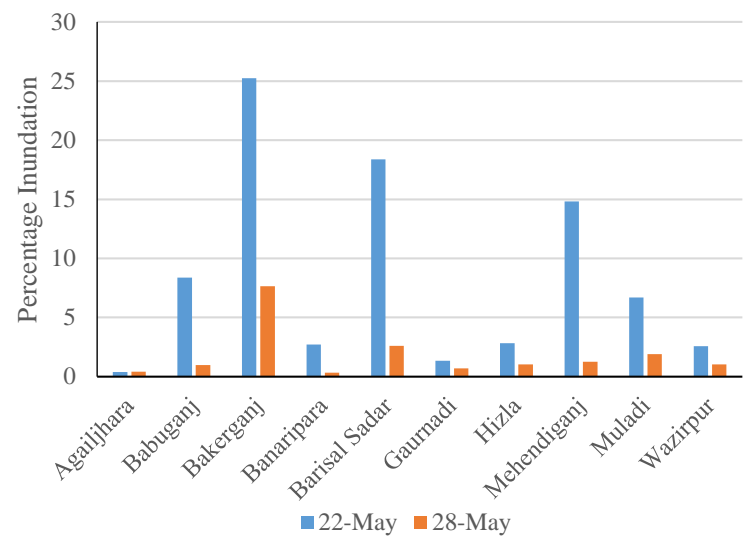

(c) Barisal District

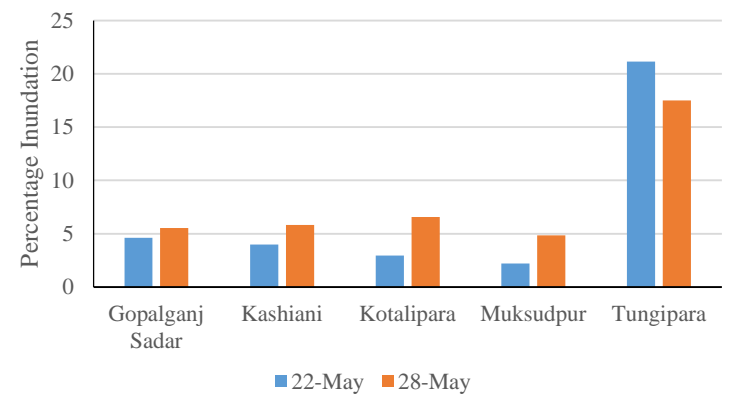

(e) Gopalganj District

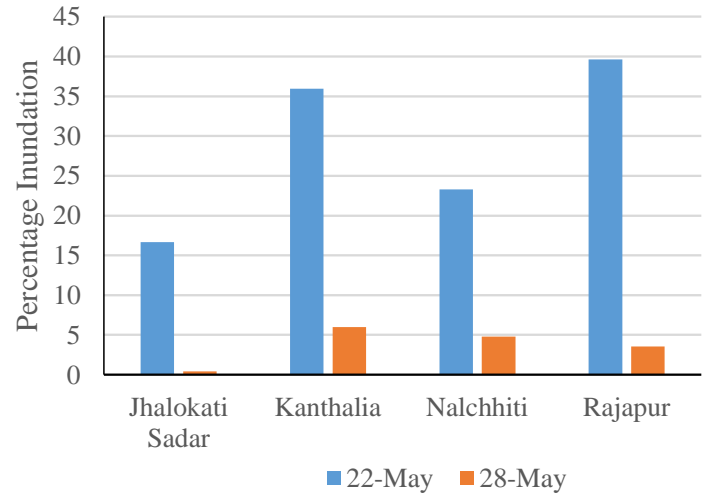

(g) Jhalokati District

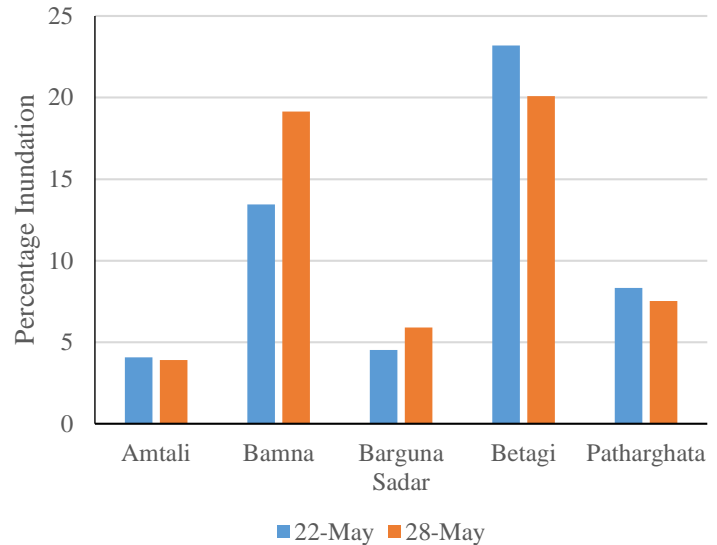

(b) Barguna District

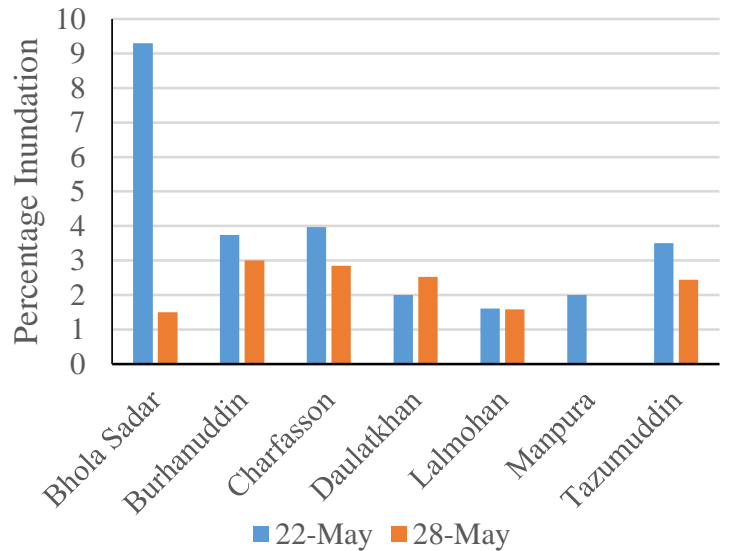

(d) Bhola District

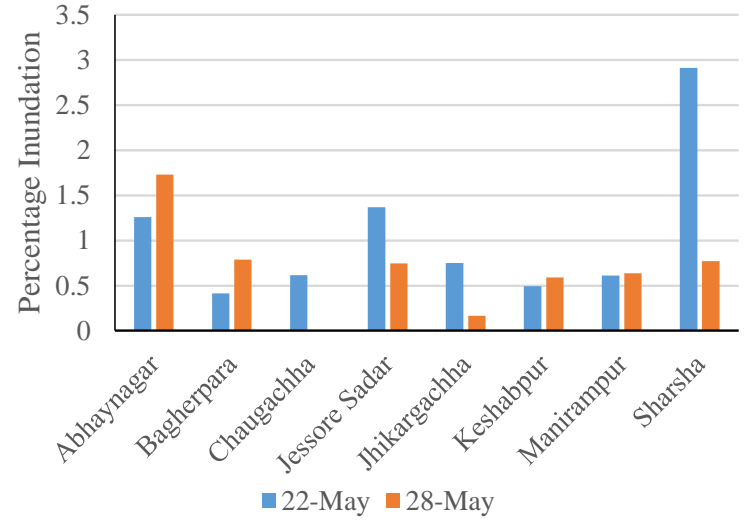

(f) Jessore District

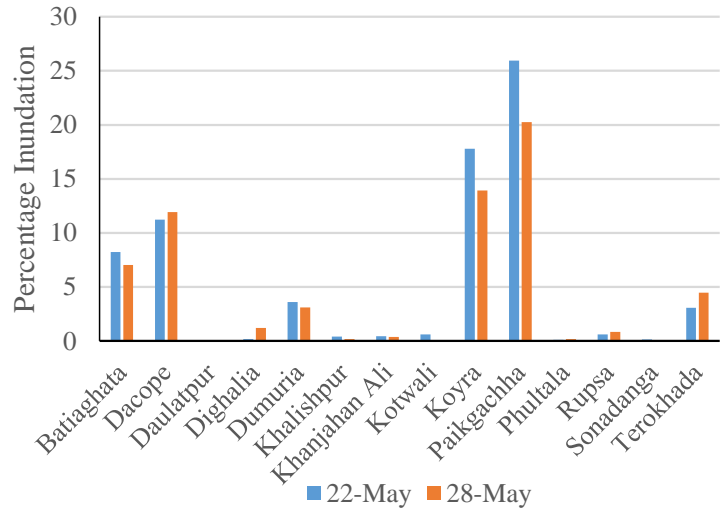

(h) Khulna District 


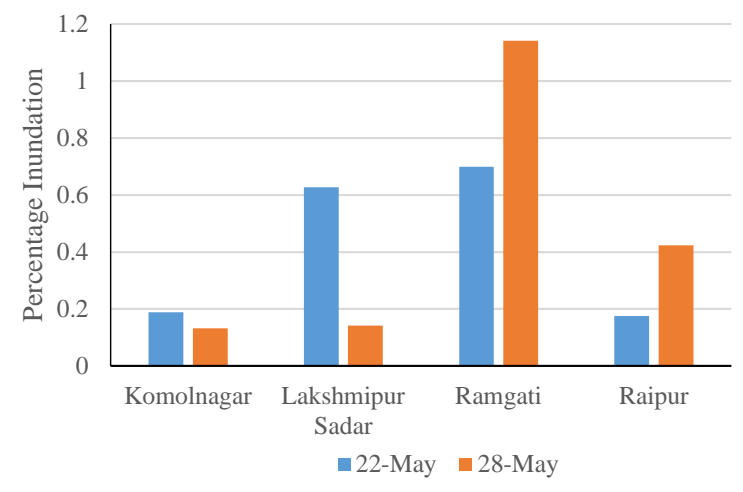

(i) Lakshmipur District

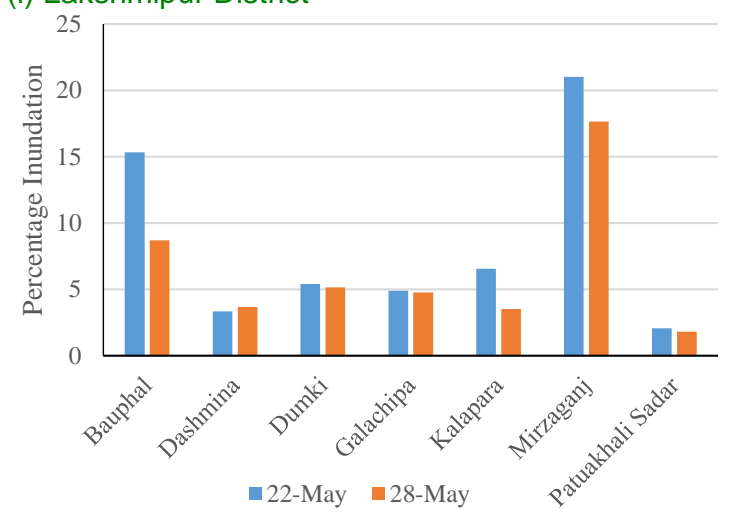

(k) Patuakhali District

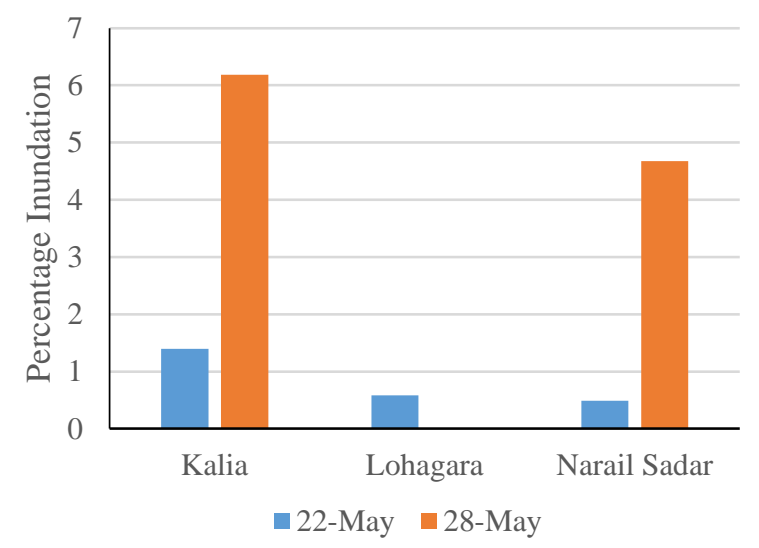

(j) Narail District

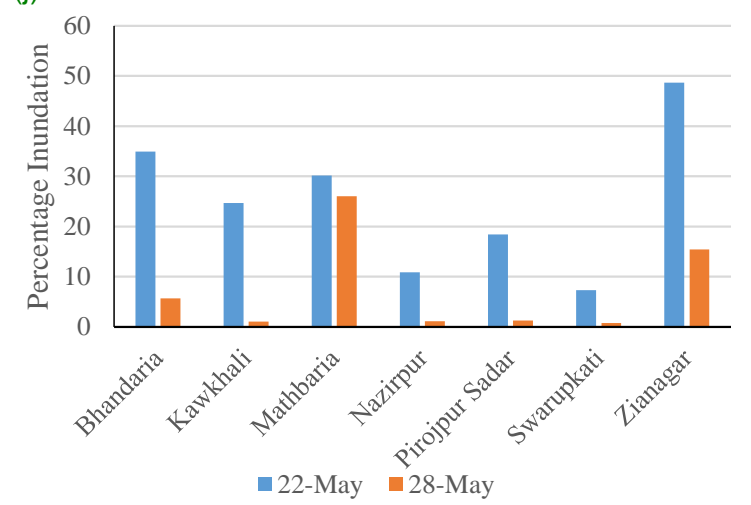

(I) Pirojpur District

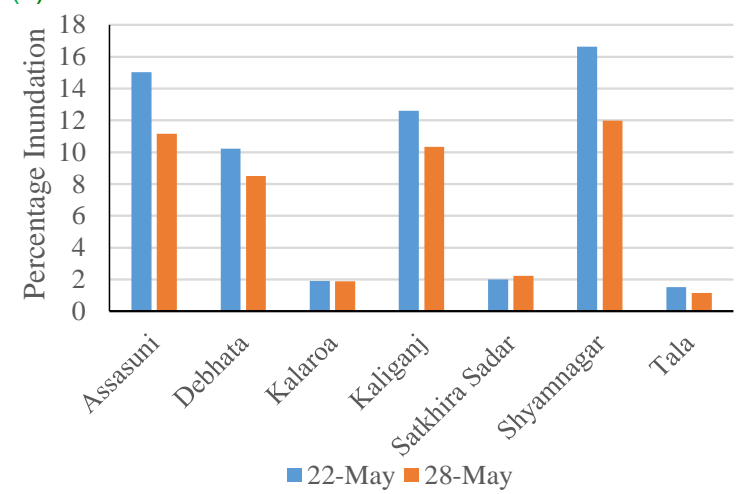

(m) Satkhira District

Figure 4. Inundation areas are represented in percentage on 22 May, and 28 May in flood-affected Upazilas.

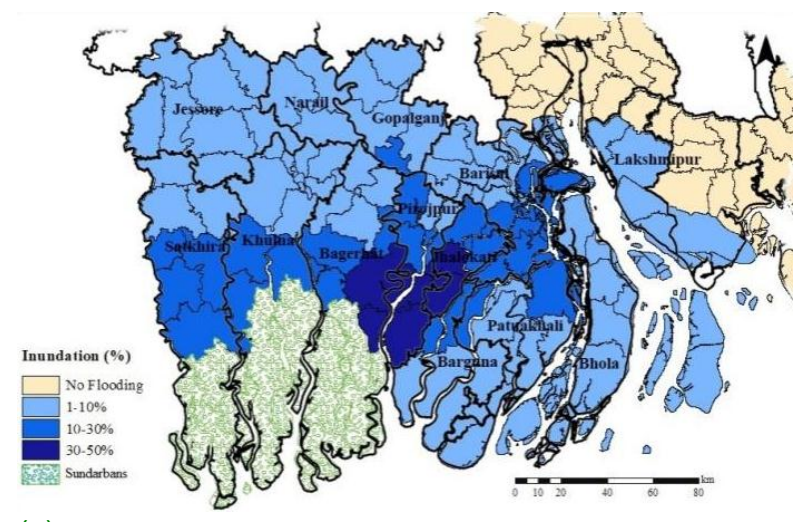

(a)

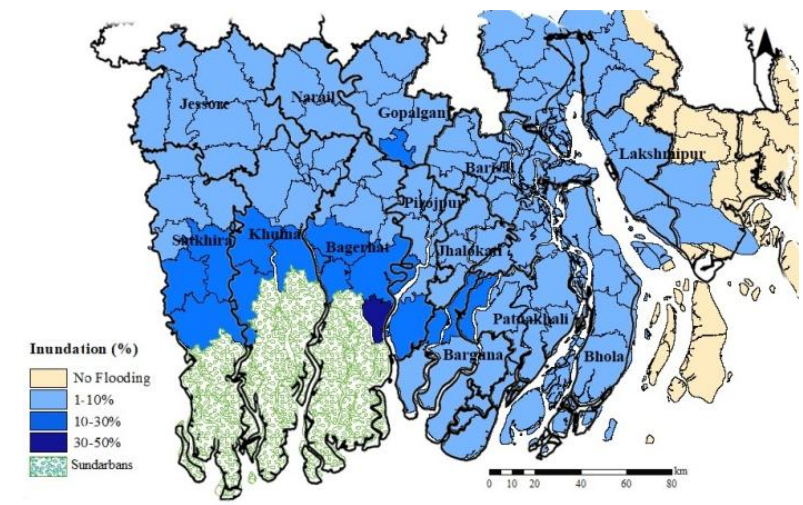

(b)

Figure 5. Inundation area of affected Upazilas is shown as a percentage of the total area (a) refers to the flooding scenario 22 May, (b) refers to the flooding scenario of 28 May 
Figure 5 shows the creation of two inundation maps based on the flood area calculation on 22and 28 May. These regions are represented in the percentage of the total affected Upazila and the maps represented the spatial and temporal extent of the flood. However, the flood water became very persistent after crossing the Sundarbans, along the mangrove forest. This circumstance is easily comprehended by closely comparing these two inundation maps.

\subsection{Validation}

In the validation of image processing results, comparisons were formed with both secondary datasets, including the NAWG field survey, and a machine learning approach, known as SVM using the SAR data. Table 2 compares the findings of these two inundation studies in the affected districts. The affected area variation for several regions was calculated. Jhalokati obtained the maximum percentile variation at $6.9 \%$, while Jessore was 5.1\%. These two locations were both evaluated on 22 May 2020, but the remaining districts, ranged between 0.5-2.5\%. Furthermore, most territories showed similar results from these two distinct processes.

The present research results were also compared with another data source, an inundation map
(Figure 6) prepared from the validation survey by Needs Assessment Working Group (NAWG), Bangladesh. This illustration showed the severity of the union-level flooding scenario due to the Amphan cyclone. The unions with inundation areas above $50 \%$ were presented with red, while the ranges of $1-25 \%$ and $25-50 \%$ denoted dark and light orange, respectively.

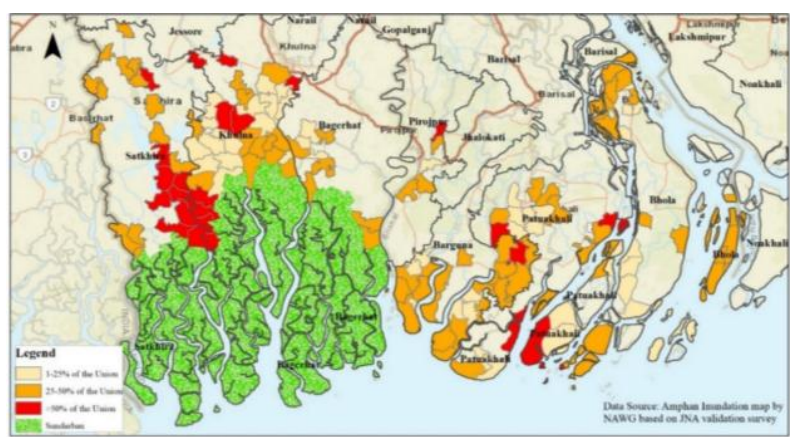

Figure 6. Inundation map based on JNA validation survey by NAWG, Bangladesh.

Subsequently, the union-level inundation data was compared to the flood map generated for 22 May 2020 (Figure 7), with the flooded areas represented in blue. The level of inundation in the affected unions was very similar in both maps and the reference illustration was prepared using the primary data from the validation survey. Therefore, the study findings positively reflected the actual flood conditions.

Table 2. Inundation areas in affected districts found in this study are compared with the inundation areas found using the SVM method (Hassan et al., 2020)

\begin{tabular}{|c|c|c|c|c|c|}
\hline \multirow[b]{2}{*}{ District } & \multirow[b]{2}{*}{ Division } & \multicolumn{2}{|c|}{22 May 2020} & \multicolumn{2}{|c|}{28 May 2020} \\
\hline & & $\begin{array}{l}\text { Inundation } \\
\text { Area }\left(\mathrm{km}^{2}\right)\end{array}$ & $\begin{array}{l}\text { Inundation } \\
\text { Area }\left(\mathrm{km}^{2}\right) \\
\text { (Hassan et al., 2020) }\end{array}$ & $\begin{array}{l}\text { Inundation } \\
\text { Area }\left(\mathrm{km}^{2}\right)\end{array}$ & $\begin{array}{l}\text { Inundation } \\
\text { Area }\left(\mathrm{km}^{2}\right) \\
\text { (Hassan et al., 2020) }\end{array}$ \\
\hline Bagerhat & Khulna & 375 & 335 & 321 & 274 \\
\hline Pirojpur & Barisal & 300 & 249 & 128 & 85 \\
\hline Satkhira & Khulna & 239 & 213 & 186 & 159 \\
\hline Khulna & Khulna & 238 & 173 & 203 & 142 \\
\hline Barisal & Barisal & 238 & 211 & 58 & 61 \\
\hline Jhalokati & Barisal & 220 & 162 & 29 & 21 \\
\hline Patuakhali & Barisal & 204 & 188 & 149 & 109 \\
\hline Barguna & Barisal & 117 & 108 & 119 & 95 \\
\hline Bhola & Barisal & 85 & 105 & 44 & 54 \\
\hline Gopalganj & Dhaka & 71 & 126 & 99 & 142 \\
\hline Jessore & Khulna & 32 & 190 & 19 & 120 \\
\hline Narail & Khulna & 9 & 27 & 57 & 82 \\
\hline Lakshmipur & Chittagong & 6 & 21 & 5 & 18 \\
\hline
\end{tabular}




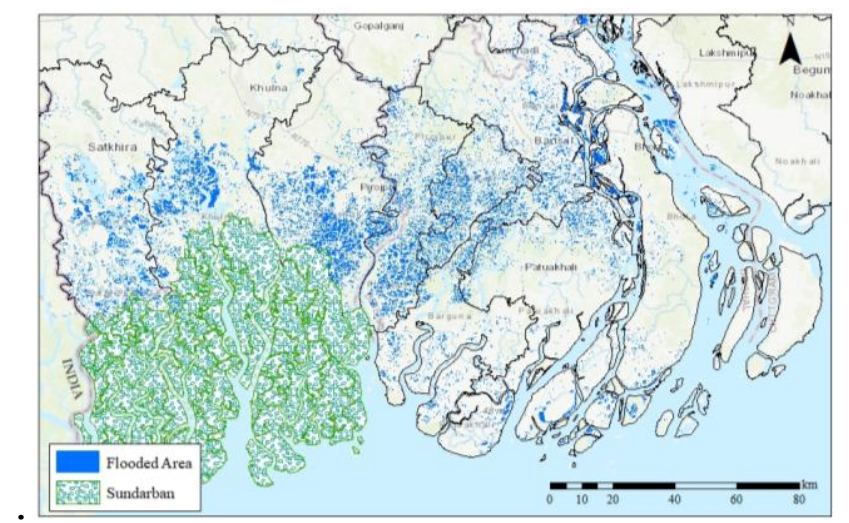

Figure 7. Inundation map for the flooding caused by cyclone Amphan on 22 May 2020

\section{CONCLUSION}

The purpose of this study was to construct a flood inundation map due to Amphan cyclone, using SAR data. This effort is possibly achieved by applying a methodology that combines change detection and thresholding (CDAT) methods. Subsequently, the inundated areas were analyzed with geospatial tools. $\mathrm{km}^{2}$ The results showed an inundated landmass of $2146 \mathrm{~km}^{2}$, excluding the Sundarban. In addition, Bagerhat, Pirojpur, Satkhira, Khulna, Barisal, Jhalokati, Patuakhali, and Barguna obtained the most coverage. Therefore, the flood magnitude tends to aggravate the prevalent situation, despite declining to $1429 \mathrm{~km}^{2}$ after seven $\mathrm{km}^{2}$ days. The floods were reportedly caused by heavy rainfall triggered, leading to several structural breaches. A total of $550 \mathrm{~km}$ of roads and embankments were relatively damaged, according to a field survey (Needs Assessment Working Group, 2020). The analysis results were subsequently compared with an inundation map. This diagram was designed using a validation survey by NAWG, Bangladesh, immediately after the Amphan event. Also, the present study was assessed with a previous related investigation using SAR data based on a machine learning technique, SVM. In this regard, a reasonable match was obtained, and the study findings are assumed to offer viable guidance for future decision support systems.

\section{DISCLAIMER}

The authors declare no conflict of interest.

\section{AVAILABILITY OF DATA AND MATERIALS}

All data are available from the corresponding author.

\section{ACKNOWLEDGMENTS}

This research was supported by the funds provided for the first author undergoing a Master of Science program in Civil Engineering, Chittagong University of Engineering and Technology (CUET), Bangladesh. The authors are grateful to BWDB, CPA, and NAWG for providing the necessary bathymetric, meteorological, and validation data, respectively.

\section{REFERENCES}

Ali, A., 1999. Climate change impacts and adaptation assessment in Bangladesh. Climate Research, 12(2-3 SPEC. ISS. 6), pp.109-116.

Aristizabal, F., Judge, J. and Monsivais-Huertero, A., 2020. High-resolution inundation mapping for heterogeneous land covers with synthetic aperture radar and terrain data. Remote Sensing, 12(6).

Brisco, B., Short, N., Van Der Sanden, J., Landry, R. and Raymond, D., 2009. A semi-automated tool for surface water mapping with RADARSAT1. Canadian Journal of Remote Sensing, 35(4), pp.336-344.

Brivio, P.A., Colombo, R., Maggi, M. and Tomasoni, R., 2002. Integration of remote sensing data and GIS for accurate mapping of flooded areas. International Journal of Remote Sensing, 23(3), pp.429-441.

Chaabani, C., Chini, M., Abdelfattah, R., Hostache, R. and Chokmani, K., 2018. Flood mapping in a complex environment using bistatic TanDEM-X/TerraSAR-X InSAR coherence. Remote Sensing, 10(12), pp.1-20.

Chowdhury, E.H. and Hassan, Q.K., 2017. Use of remote sensing data in comprehending an extremely unusual flooding event over southwest Bangladesh. Natural Hazards, 88(3), pp.1805-1823. 
Cian, F., Marconcini, M. and Ceccato, P., 2018. Normalized Difference Flood Index for rapid flood mapping: Taking advantage of EO big data. Remote Sensing of Environment, 209(February), pp.712-730.

Clement, M.A., Kilsby, C.G. and Moore, P., 2018. Multi-Temporal SAR Flood Mapping using Change Detection.

Dasgupta, S., Huq, M., Khan, Z., Ahmed, M., Mukherjee, N., Khan, M. and Pandey, K., 2010. Vulnerability of Bangladesh to Cyclones in a Changing Climate: Potential Damages and Adaptation Cost. World Bank Policy Research Working Paper, (5280).

Debsarma, S.K., 2009. Simulations of storm surges in the Bay of Bengal. Marine Geodesy, 32(2), pp.178-198.

ESA, 2012. ESA's radar observatory mission for GMES operational services. [online] ESA Special Publication, Available at: <https://sentinel.esa.int/documents/247904/349 449/S1_SP-1322_1.pdf $>$.

Hassan, M.M., Ash, K., Abedin, J., Paul, B.K. and Southworth, J., 2020. A quantitative framework for Analyzing spatial dynamics of flood events: A case study of super cyclone Amphan. Remote Sensing, 12(20), p.26.

Henry, J.B., Chastanet, P., Fellah, K. and Desnos, Y.L., 2006. Envisat multi-polarized ASAR data for flood mapping. International Journal of Remote Sensing, 27(10), pp.1921-1929.

Hoque, R., Nakayama, D., Matsuyama, H. and Matsumoto, J., 2011. Flood monitoring, mapping and assessing capabilities using RADARSAT remote sensing, GIS and ground data for Bangladesh. Natural Hazards, 57(2), pp.525-548.

Horritt, M.S., 1999. A statistical active contour model for SAR image segmentation. Image and Vision Computing, 17(3-4), pp.213-224.

Hostache, R., Matgen, P. and Wagner, W., 2012. Change detection approaches for flood extent mapping: How to select the most adequate reference image from online archives? International Journal of Applied Earth Observation and Geoinformation, [online] 19(1), pp.205-213. Available at: <http://dx.doi.org/10.1016/j.jag.2012.05.003>.

Huang, C., Chen, Y. and Wu, J., 2014. Mapping spatio-temporal flood inundation dynamics at large riverbasin scale using time-series flow data and MODIS imagery. International Journal of Applied Earth Observation and Geoinformation, [online] 26(1), pp.350-362. Available at: <http://dx.doi.org/10.1016/j.jag.2013.09.002>.

Insom, P., Cao, C., Boonsrimuang, P., Liu, D., Saokarn, A., Yomwan, P. and Xu, Y., 2015. A Support Vector Machine-Based Particle Filter Method for Improved Flooding Classification. IEEE Geoscience and Remote Sensing Letters, 12(9), pp.1943-1947.

Islam, A.S., Bala, S.K. and Haque, M.A., 2010. Flood inundation map of Bangladesh using MODIS time-series images. Journal of Flood Risk Management, 3(3), pp.210-222.

Long, S., Fatoyinbo, T.E. and Policelli, F., 2014. Flood extent mapping for Namibia using change detection and thresholding with SAR. Environmental Research Letters, 9(3).

Martinis, S., Kersten, J. and Twele, A., 2015. A fully automated TerraSAR-X based flood service. ISPRS Journal of Photogrammetry and Remote Sensing, [online] 104, pp.203-212. Available at: <http://dx.doi.org/10.1016/j.isprsjprs.2014.07.0 $14>$.

Mason, D.C., Horritt, M.S., Dall'Amico, J.T., Scott, T.R. and Bates, P.D., 2007. Improving river flood extent delineation from synthetic aperture radar using airborne laser altimetry. IEEE Transactions on Geoscience and Remote Sensing, 45(12), pp.3932-3943.

Mason, D.C., Schumann, G.J.P., Neal, J.C., Garcia-Pintado, J. and Bates, P.D., 2012. Automatic near real-time selection of flood water levels from high resolution Synthetic Aperture Radar images for assimilation into hydraulic models: A case study. Remote Sensing 
of Environment, [online] 124, pp.705-716. Available at: <http://dx.doi.org/10.1016/j.rse.2012.06.017>.

Mason, D.C., Speck, R., Devereux, B., Schumann, G.J.P., Neal, J.C. and Bates, P.D., 2010. Flood detection in Urban areas using TerraSAR-X. IEEE Transactions on Geoscience and Remote Sensing, 48(2), pp.882-894.

Matgen, P., Hostache, R., Schumann, G., Pfister, L., Hoffmann, L. and Savenije, H.H.G., 2011. Towards an automated SAR-based flood monitoring system: Lessons learned from two case studies. Physics and Chemistry of the Earth, [online] 36(7-8), pp.241-252. Available at: <http://dx.doi.org/10.1016/j.pce.2010.12.009>.

Murty, T.S., Flather, R.A. and Henry, R.F., 1986. The storm surge problem in the bay of Bengal. Progress in Oceanography, 16(4), pp.195-233.

Needs Assessment Working Group, 2020. Cyclone Amphan Joint Needs Assessment (JNA).

Nico, G., Pappalepore, M., Pasquariello, G., Refice, A. and Samarelli, S., 2000. Comparison of SAR amplitude vs. coherence flood detection methods - a GIS application. International Journal of Remote Sensing, 21(8), pp.1619-1631.

RSMC-Tropical Cyclones, N.D., 2021. Report on cyclonic disturbances over the north Indian Ocean during 2019.

Sarker, C., Mejias, L., Maire, F. and Woodley, A., 2019. Flood mapping with convolutional neural networks using spatio-contextual pixel information. Remote Sensing, 11(19), pp.1-25.

Schlaffer, S., Chini, M., Giustarini, L. and Matgen, P., 2017. Probabilistic mapping of floodinduced backscatter changes in SAR time series. International Journal of Applied Earth Observation and Geoinformation, [online] 56, pp.77-87. Available at: <http://dx.doi.org/10.1016/j.jag.2016.12.003>.

Schumann, G., Di Baldassarre, G., Alsdorf, D. and Bates, P.D., 2010. Near real-time flood wave approximation on large rivers from space:
Application to the River Po, Italy. Water Resources Research, 46(5), pp.1-8.

Singha, M., Dong, J., Sarmah, S., You, N., Zhou, Y., Zhang, G., Doughty, R. and Xiao, X., 2020. Identifying floods and flood-affected paddy rice fields in Bangladesh based on Sentinel-1 imagery and Google Earth Engine. ISPRS Journal of Photogrammetry and Remote Sensing, [online] 166(January), pp.278-293. Available at: <https://doi.org/10.1016/j.isprsjprs.2020.06.011 $>$.

Tehrany, M.S., Pradhan, B., Mansor, S. and Ahmad, N., 2015. Flood susceptibility assessment using GIS-based support vector machine model with different kernel types. Catena, [online] 125, pp.91-101. Available at: $<$ http://dx.doi.org/10.1016/j.catena.2014.10.017 $>$.

Tien Bui, D., Hoang, N.D., Martínez-Álvarez, F., Ngo, P.T.T., Hoa, P.V., Pham, T.D., Samui, P. and Costache, R., 2020. A novel deep learning neural network approach for predicting flash flood susceptibility: A case study at a high frequency tropical storm area. Science of the Total Environment, [online] 701, p.134413. Available at:

$<$ https://doi.org/10.1016/j.scitotenv.2019.13441 3>.

Torres, R., Snoeij, P., Geudtner, D., Bibby, D., Davidson, M., Attema, E., Potin, P., Rommen, B.Ö., Floury, N., Brown, M., Traver, I.N., Deghaye, P., Duesmann, B., Rosich, B., Miranda, N., Bruno, C., L'Abbate, M., Croci, R., Pietropaolo, A., Huchler, M. and Rostan, F., 2012. GMES Sentinel-1 mission. Remote Sensing of Environment, [online] 120, pp.9-24. Available at: <http://dx.doi.org/10.1016/j.rse.2011.05.028>.

Twele, A., Cao, W., Plank, S. and Martinis, S., 2016. Sentinel-1-based flood mapping: a fully automated processing chain. International Journal of Remote Sensing, 37(13), pp.2990-3004.

Uddin, K., Matin, M.A. and Meyer, F.J., 2019. Operational flood mapping using multitemporal Sentinel-1 SAR images: A case study 
from Bangladesh. Remote Sensing, 11(13).

Woznicki, S.A., Baynes, J., Panlasigui, S., Mehaffey, M. and Neale, A., 2019. Development of a spatially complete floodplain map of the conterminous United States using random forest. Science of the Total Environment, [online] 647, pp.942-953. Available at: $<$ https://doi.org/10.1016/j.scitotenv.2018.07.353 $>$. 